\title{
Artistic Teaching about Jia Pingwa's Prose in an Era of Visualization Zhang Ying
}

\author{
School of Humanities, Xi'an University, Xi'an, Shaanxi 710065
}

Keywords: Visualization; Jia Pingwa; prose; artistic characteristics

\begin{abstract}
Today, with the rapid development of visual culture, colorful images make readers enter the "era of reading pictures" unconsciously. Images bring the readers visualization, audio-visual impact and reading comprehensiveness. When teaching about the artistic characteristics of Jia Pingwa's proses, it is suggested to adopt the teaching mode of prose visualization to conduct imagery interpretation of related conditions and customs in sketchy and freehand way which are involved in his prose works, coupled with imaging factors such as beautiful pictures and moving music, so as to attract students to enter the unique artistic conception created by Jia Pingwa's proses, and guide them to feel the artistic characteristics embodied in Jia Pingwa's proses gradually.
\end{abstract}

Traditional literary works and image works are interactional and interpenetrative for almost a century. Literary works in paper cannot excite readers' keen interest any longer; comparatively speaking, readers prefer to spend their time and energy on rich and vivid image world which is created by advanced modern media technology. Today, with the rapid development of visual culture, colorful images make readers enter the "era of reading pictures" unconsciously. Images bring the readers visualization, audio-visual impact and reading comprehensiveness. Images filter out heavy cultural thinking carried in literary works, and lead readers to see and taste the works in a relaxed atmosphere. In such special cultural context, traditional literary works boom in video form. Literature and movie interact with each other in an unprecedented sense of closeness: on the one hand, literary works can realize "sensational effect" in virtue of image propagation, convert the role of audience to reader, and reproduce the resplendence of paper literature. Writers add some imaging factors into the literary creation unconsciously, so as to promote the development of literature towards visualization. On the other hand, excellent and high box-office videoed literary works is inseparable from good scripts, and it is undoubted that excellent literary works provide precious resources for image creation. As the essayist Li Jingze said, "literary works can provide a rich matrix and a fertile land for movies and TV plays. The fruit on the land is definitely incomparable to potted fruit." Thus, with the multi-culture development nowadays, although visual culture characterized by image is dominated, the charm of literature still exits. Literary works depict characters, describe things, and express emotion with language as the media, which is unique and irreplaceable by image works. Literary works and image works will always coexist and co-enrich people's ever-changing spiritual life.

Jia Pingwa is a famous contemporary novelist and excellent proser. He went to study in Chinese Department of Northwest University in 1972 and then worked as an editor after graduation. He started writing from 1973 in such fields as poem, novel, essay, reportage and literary review. His published works include long novels Turbulence and Deserted City and collected prose Moon Trace, Love Trail, Heart Trace, Human Trace and Jia Pingwa's Prose Selection.

Making a general survey of his prose, we can find that most of his prose is based on Shangzhou where he was born and grew up and describes mountains and vegetation as well as local conditions and customs there. For example, in his prose Ugly Stone, Jia Pingwa said: I used to feel sorry for that ugly black piece of stone lying like an ox in front of our door; none knew when it was left there and none paid any attention to it, except at the time when wheat was harvested and my grandma, seeing the grains of wheat spread all over the ground in the front yard of the house, would grumble: "This ugly stone takes so much space. Move it away someday." Thus my uncle had wanted to use it for the gable when he was building a house, but he was troubled to find it of very irregular shape, with no edges nor corners, nor a flat plane on it. And he wouldn't bother to break it in half with a chisel because the river bank was nearby, where he could have easily fetched a much better stone 
instead. Even when my uncle was busy with the flight of steps leading to the new house he didn't take a fancy to the ugly stone. One year when a mason came by, we asked him to make us a stone mill with it. As my grandma put it, "Why not take this one, so you won't have to fetch one from afar." But the mason took a look and shook his head: He wouldn't take it for it was of too fine a quality.

In his prose My Primary School, Jia Pingwa wrote: my primary school is in a temple full of very high houses with dragons and animals curved on the ridge and green moss spreading along the tile groove all the year round as well as a kind of grass which will slowly grows up to half a foot in rainy days. Teachers live in the temple hall where there was a statue of Guan Yu. The statue had a purplish red face and was later moved away with its mud pedestal used for building yard and its eyeballs (two glazed porcelain balls, gleaming at night) put on the top of the screen wall facing the gate. Bungalows at both sides serve as classrooms where only senior students have classes. High steps are set for the bungalows. I can jump down from them with both feet but cannot jump onto them unless I turn to the corner of the gable wall and then I can effortlessly jump with one foot onto the steps from the cobbled road. At the corner of the gable wall, there is an old cracking bead tree. On the top of the tree, there is a crow nest as large as a sieve. Under the nest, a bell hangs on a branch. Every time the bell rings, the whole family of crows has no reaction at all. This strange phenomenon has confused me for years.

In his prose Longju Village, Jia Pingwa wrote: across the town, the market day is on the first, fourth and seventh day, or the second, fifth and eighth day, or the third, sixth and ninth day. While at Longju village, no matter on which day in which month and no matter in the morning or evening, people are always all around. For villagers, this place of hundred miles is like Beijing or Shanghai; they feel proud, across the whole life, of going here. Every time they come into the town, the crossroad for them is Wangfujing of Beijing or Nanjing Road of Shanghai; not for dealing but just for widening their vision, they feel happy, even when they sweat a lot among the crowd or lose their shoes for crowding or their wallets are stolen. Those living in mountains especially like going into the town; they will get up with new clothes as soon as a cock crows and then carry wood, potatoes, dried persimmons, funguses, walnuts, herbs and animal skins to sell at the marketplace of the town, or they will carry baskets on their backs or empty ones on their arms or wind leather ropes around their waists and put carrying poles on their shoulders and then go in and out of large and small shops to browse various goods. "Hey, hey," they will call a salesclerk like this; the salesclerk will complain: "Are you calling a dog?" Then they will say "comrade!" like city people do but feel awkward. If they ask for "foreign alkali", "foreign basin" and "foreign umbrella", the salesclerk will complain again: "There are no foreign goods here." Then they will blush but feel happy after going out. Then they will walk along the street, watching monkey tricks and sugar figure making, hanging around in book shops and painting shops, and seeing advertisements before a cinema and notices before a court (Though they are illiterate, they will remember all news with their sharp ears.) Then they will go into a private barbershop to make their hair separated into two parts stuck together by the thick hair oil. Then they will go to a restaurant proudly, ordering a beancurd casserole, a plate of braised pig's ears with soy sauce, three pieces of steamed bread, and a bowl of egg soup, and then eat up them with their mouths filled with oil and sweat on their foreheads. Businessmen in the town most welcome this kind of customers, for they can make money from them and make fun of their simple minds. Thus, these villagers are satisfied and city people are also satisfied.

Jia Pingwa's prose is full of his living experiences in the country, involving natural scenery such as mountains, rivers and vegetation; cultural scenery like temples, market and ugly stone described in interesting local dialects; and generous Shangzhou people who drink Xifeng liquor, have mutton and bread pieces in soup and sing Shaanxi Opera, all of which give off warm country flavor and rich rusticity, featuring distinctive artistic characteristics.

Jia Pingwa's prose has a most prominent artistic characteristic, i.e. obvious regional feature and profound implication of national culture. When evaluating Jia Pingwa's prose, Sun Li said, "Jia Pingwa has the base, the living base....he, on his own cultivated land, makes a wide collection. Diligently and conscientiously, with confidence but without complaint, he ploughs. He, on his own 
road, goes forward steadily". This evaluation has revealed accurately the regional feature in Jia Pingwa's prose. Jia Pingwa, through his unique intelligence and great passion, shows to readers vivid and distinctive pictures of local color in his prose. For example, in First Record of Shangzhou, he has mentioned the standard to judge whether a family in Shangzhou is rich is "to see whether the family have stored in their cellar sugar cane wine of two to three years and have hung on the wall half to one piece of bacon."; in Shaanxi Opera, he has written Qinchuan (Shaanxi plain) people love singing Shaanxi Opera, allegro for happy time and adagio for sad time, thus expressing happiness or sadness in their heart; in Discussion on Guanzhong (central Shaanxi), he has discussed images of Shaanxi people, drinking Xifeng liquor, having mutton and bread pieces in soup and singing Shaanxi Opera. Jia Pingwa has a very high historical and cultural literacy, thus being knowledgeable about historical and cultural traditions of Guanzhong Qinchuan plain, Shaanxi Loess Plateau and Shannan Shangzhou upland. With survey on the traditional national culture from a modern perspective in his prose, Jia Pingwa has shown his cordial and appreciative feeling about it on the one hand. For example, in Shaanxi Opera, he has mentioned the ardent love of Guanzhong people for the old Chinese opera art - Shaanxi Opera; in Five-flavor Alley, he has described people of the "five-flavor alley" are honest, kind and tolerant and they can respect and care for each other despite of their different occupation and culture; in A Little Knowledge on Henan Alley, he has described the good moral characters of Henan people in Henan alley, such as they are hard-working, amiable, tolerant and upright and they never stop improving themselves. On the other hand, he also has criticized the conservative and backward awareness in the traditional national culture. For example, in Discussion on Guanzhong, he has exposed the habitual laziness of Guanzhong people; in Second Record of Shangzhou - III, he has criticized the people who are conservative, prejudiced and content with the status quo and have feudal thought but no sense of innovation; in prose such as A Place of Stubbornness, I am a Farmer and Still Waters Running Deep, he has exposed greed and ferociousness of people and criticized their ugly customs and behaviors.

Jia Pingwa's prose has another prominent characteristic, i.e. natural and genuine philosophical spirit. Jia Pingwa adores nature; in his prose, he shows completely his appreciation and admiration for the natural world and how he tries to ascribe his life to nature, comply with nature and be dominated by mysterious law of nature. In Notes on Observation of Grit, he has written like this: "Fishes in water swim back and forth vigorously and leisurely but will become dying with degenerated wings and unmoving tail if caught out of water; birds in sky fly singing at leisure but will become unable to fly with wings or scratch with claws if falling down into water. Everything existing in the world will not be able to show its vitality, inherent qualities or value unless it is existent in the nature belonging to it." In Visiting Orchids, he has written: orchids growing in the wild beside water receive spirit of nature and show various poses with natural beauty; if potted, they become more luxuriant with more tender leaves, "but too beautiful and too charming, thus showing garish style." A researcher Fei Bingxun said when commenting on Jia Pingwa's prose, "We can obtain from most of Jia Pingwa's prose such a proposition - being natural is living and losing nature is losing life. Pieces of gravel on beach shine charmingly but become gloomy as soon as picked up in hands." Jia Pingwa holds the view of freedom and returns to his original nature, for he is influenced by Taoist Philosophy without a doubt. Jia Pingwa puts such attitude of admiring nature and returning to nature in his prose describing natural things and unique attitude towards life in those describing culture and persons.

Jia Pingwa's prose has a third characteristic, i.e. his detached, dispirited and weird attitude towards life. A researcher Chen Xiaoming said, "Jia Pingwa's attitude towards life includes profound conflict, for he admires nature and believes in destiny but also has some cultural peculiarities and for he pursues detached optimism but is also dispirited and indulges himself; on the whole, Jia Pingwa's attitude towards life tends to be dispirited and weird." In prose, Jia Pingwa often shows some attitudes and ideas different from common sense or those common people have; he likes decadent things and indulges in gloom and weirdness; with strange natural endowment, he always pays attention to weird but unique local conditions and customs. Just because of this, his prose appears new and unusual. Jia Pingwa often shows in his prose a dispirited attitude towards 
life, which he considers as negative freedom after he sees through the world; besides, he also expresses an open-minded feeling which is somewhat relevant to his admiration for Zen and Buddhism. For example, in his works such as Climbing Jiguan Mountain, Reading Mountain, Asparagus Fern, Buddhist Service and Three-eye Stone, he has expressed his ambition by means of objects he described, thus showing his open and lofty feeling; in Tower of Famen Temple, Red Rock Canyon and Huangfu Valley, he has revealed such feeling that tremendous changes happen in the world and life is impermanent.

Instead of grandiloquent, flowery and complex language, Jia Pingwa just applies simple, elegant and appealing words to make readers immersed in artistic atmosphere. Take for example a paragraph in A Letter of Reading Advice for Little Sister to be Eighteen: "For so many years, I have lived a simple rather than an extravagant life, for fear of forgetting the hard life in the past. I could not have forgotten the past; I have spent all my money buying books. Therefore, for your birthday, I will send you nothing but a set of famous book with ten volumes, hoping you are happy." This paragraph is composed of concise words which make readers feel cordial and aesthetic in simplicity. Take another example, a paragraph in Second Record of Shangzhou: "What can most endure loneliness is the mountain in winter, which becomes thin, pure and clear, with disappearing red and green, thus looking like a woman coming from the royal palace into the outside world, seeming degenerated maybe, but returning to her original appearance. Stones, completely exposed, lie among vegetation, partly hidden and partly visible. Vegetation is not defeated and what withers is weakness, with stiff branches and leaves ringing like a bell in the wind. Is winter the season of bones? Or the season of force?" This paragraph consists of short sentences which are natural, fluent, lofty, elegant and interesting and show completely the strong spirit and charm of the mountain.

On the whole, Jia Pingwa's prose is quite vigorous, casual, simple and depressed, with honest emotion and uncanny implication. Jia Pingwa writes his prose in a very different way, showing a unique scenery of the contemporary prose world.

In an era of visualization, even if paper novels have strong plot, it is hard to interest the readers, let alone graceful proses which are shape-dispersing but spirit-concentrating. In rapid and modern lifestyle nowadays, people always feel impatient, and pursue efficiency and convenience when receiving culture, they prefer to understand literary works in an intuitive and reflexed way. For college students, they are more receivable to literary works in an all-around experience way which integrates vision, audio and feeling. Teaching about literary works in visualization has become imperative, especially for prosaic literary works.

When teaching about the artistic characteristics of Jia Pingwa's proses, it is suggested to adopt the teaching mode of prose visualization to conduct imagery interpretation of related conditions and customs in sketchy and freehand way which are involved in his prose works, coupled with imaging factors such as beautiful pictures, moving music and affectionate reading, so as to attract students to enter the unique artistic conception created by Jia Pingwa's proses, and guide them to feel the artistic "beauty" embodied in Jia Pingwa's proses gradually and to experience obvious regional feature, profound implication of national culture, natural and genuine philosophical spirit, detached, dispirited and weird attitude towards life, and simple, elegant and appealing words instead of grandiloquent, flowery and complex language to make readers immersed in artistic atmosphere. Compared with such teaching mode of prose visualization, traditional teaching mode of guiding students to read and study prose works seems to be dull, boring and obsolete, which is difficult to arouse the enthusiasm of students and achieve a good teaching effect.

\section{Acknowledgements}

This paper is the achievement of Xi'an Social Science Planning Fund Project "Research on Xi'an Literary Visualization". Project No.: 16WL11 


\section{References}

[1] Peng Shenghua. On the Influence of Jia Pingwa's Childhood Complex on His Literature Creation [J]. Journal of Xinyang Normal University (Philosophy and Social Sciences Edition), 2008, $28(3)$

[2] He Guangchao. Aesthetic Pursuit in Writing Process of Jia Pingwa's Proses [J]. Journal of North University of China (Social Sciences), 2005, 21 (3)

[3] Ying Weizhong. The Wild, Moon Night, Life -- Appreciation of Prose Wildness Area [J]. Appreciation of Works, 1993, (06)

[4] Chen Wenjie. "Still Waters Running Deep" -- Jia Pingwa's Prose Creation and Zen Aesthetics [J]. Journal of Language and Literature Studies. 2006, (20)

[5] Guo Zihui, Liu Xiaolan. Leaving and Returning: Yokel Mentality in Jia Pingwa's Prose [J]. The Great Wall, 2009, (8)

[6] Ying Weizhong. Conjecture of Jia Pingwa's Recent Proses [J]. Contemporary Writers Review, 1993, (5)

[7] Xu Zhaozhen. Exploration on Language Arts of Jia Pingwa's Proses (I) [J]. Writing, 1997, (4)

[8] Sun Lili. A Sincere Friend in Flashy Society -- Reading of Jia Pingwa's Proses [J]. Times Literary (second half month), 2008, (5)

[9] Bai Zhongde. Expressing Ideology in Jia Pingwa's Prose Language [J]. Mountain Flowers, 2009, (24)

[10] Li Renzhong. Rejection of "Parsimony" -- On the Innovation of Jia Pingwa's Proses [J]. Journal of Shanghai Normal University (Philosophy and Social Sciences Edition), 1993, (1) 